\title{
EARLY INDUCTION VERSUS EXPECTANT MANAGEMENT IN TERM PROM
}

\author{
Sachin Wankhede ${ }^{1}$, Nivedita Goverdhan², Sarika Thakare3, Dinesh Daware 4
}

${ }^{1}$ Associate Professor, Department of Obstetrics and Gynaecology, Indira Gandhi Government Medical College, Nagpur. ${ }^{2}$ Senior Resident, Department of Obstetrics and Gynaecology, Indira Gandhi Government Medical College, Nagpur. ${ }^{3}$ Assistant Professor, Department of Obstetrics and Gynaecology, Indira Gandhi Government Medical College, Nagpur. ${ }^{4}$ Junior Resident, Department of Obstetrics and Gynaecology, Indira Gandhi Government Medical College, Nagpur.

\section{ABSTRACT}

\section{BACKGROUND}

The objective was to study the effectiveness and maternal and foetal outcome in term pregnancy with early induction of labour with cervical PGE2 versus expectant management.

\section{MATERIALS AND METHODS}

This is a prospective study conducted in the Department of Obstetrics and Gynaecology over a period of 1 year on a sample size of 144. Subjects were divided into two groups - Group A containing subjects with expectant management and Group B with subjects who were induced with intracervical PGE2 and their outcome was compared.

\section{RESULTS}

In Group A, 70.83\% of cases went into spontaneous labour within 24 hours and in Group B, induction was successful in $56.94 \%$ cases. Mean PROM to delivery interval was 22.36 \pm 7.04 hours for expectant group and $15.5 \pm 7.03$ hours for induction group $(\mathrm{P}=<0.0001, \mathrm{HS})$. There was significantly higher rate of vaginal deliveries in expectant group and significantly higher rate of LSCS in induction group. Neonatal antibiotic requirement was significantly higher in expectant group.

\section{CONCLUSION}

Early induction of labour in cases of PROM at term with PGE2 GEL results in reduction of latency of labour and also in increased operative intervention. Expectant management has greater maternal and neonatal morbidity.

\section{KEYWORDS}

Premature Rupture of Membranes, PROM, Labour Induction, Expectant Management.

HOW TO CITE THIS ARTICLE: Wankhede S, Goverdhan N, Thakare S, et al. Early induction versus expectant management in term PROM. J. Evolution Med. Dent. Sci. 2017;6(15):1226-1229, DOI: 10.14260/Jemds/2017/266

\section{BACKGROUND}

Premature rupture of membranes (PROM) occurs when there is a break in the continuity of the foetal membranes before the onset of labour. As a result, amniotic fluid leaks out and the amniotic cavity is exposed to the cervical and vaginal secretions. ${ }^{1}$ PROM complicates nearly $5-10 \%$ of all pregnancies, $80 \%$ of which occur at term (term PROM). ${ }^{2}$ PROM at term is generally a benign condition, with approximately $80 \%$ to $90 \%$ of women entering labour spontaneously within 24 to 48 hours without medical intervention.3,4,5,6 For these women, the prognosis for an uneventful peripartum course remains excellent, and the premature amniorrhexis can be considered a physiologic, rather than a pathologic event.7, 8 Unfortunately, $5 \%$ to $10 \%$ of women will not enter labour within 72 hours, and $2 \%$ to $5 \%$ remain undelivered 7 days following PROM at term. 4,6,9 These women are more likely to experience complications during labour and delivery.

Financial or Other, Competing Interest: None.

Submission 14-01-2017, Peer Review 08-02-2017,

Acceptance 13-02-2017, Published 20-02-2017.

Corresponding Author:

Dr. Nivedita Goverdhan,

Department of Obstetrics and Gynaecology,

Indira Gandhi Government Medical College,

Nagpur.

E-mail: niveditagoverdhan@gmail.com

DOI: $10.14260 /$ jemds/2017/266

\section{(c) (i) $(9)$}

This study was undertaken with the intention of better understanding and comparing the labour outcome in expectant management and induction of labour in patients with PROM.

\section{MATERIALS AND METHODS}

This study was a prospective study which included 144 patients with PROM, admitted to the labour room of a tertiary care hospital over one year. All pregnant women having term singleton pregnancy with cephalic presentation with PROM of less than 6 hours and cervical dilatation less than $3 \mathrm{~cm}$ were included in the study. After detailed history and thorough examination, study subjects were equally allocated to both the groups.

- Group A = 72 subjects for expectant management for 24 hrs.

In study subjects who did not go into spontaneous labour in 24 hours, induction of labour was done with intracervical PGE2.

- Group B = 72 subjects for early induction group with PROM less than 6 hours by intracervical PGE2 gel. Re induction was done for study subjects who had a poor Bishop score after 6 hours of induction.

Monitoring of foetal heart rate and uterine contractions was done in both groups.

Statistical analysis was done by using percentages, chi square test, $\mathrm{t}$ test, and $\mathrm{Z}$ test with $95 \%$ confidence interval, p-value $<0.05$ was taken as statistically significant. 
RESULTS

\begin{tabular}{|c|c|c|}
\hline $\begin{array}{c}\text { Maternal } \\
\text { Characteristics }\end{array}$ & $\begin{array}{l}\text { Expectant } \\
\text { Group (A) }\end{array}$ & $\begin{array}{l}\text { Induction } \\
\text { Group (B) }\end{array}$ \\
\hline Mean Age (in years) & $24.3 \pm 3.22$ & $23.8 \pm 3.70$ \\
\hline $\begin{array}{l}\text { Mean Gestational Age } \\
\text { (in weeks) }\end{array}$ & 38.9 & 0.89 \\
\hline Primigravida & $47(65.28 \%)$ & $53(73.61 \%)$ \\
\hline Multigravida & $25(34.72 \%)$ & $19(26.39 \%)$ \\
\hline \multicolumn{3}{|c|}{$\begin{array}{c}\text { Table 1. Distribution of Study Subjects According to } \\
\text { Maternal Characteristics }\end{array}$} \\
\hline
\end{tabular}

In expectant group (A), $51(70.83 \%)$ cases progressed to active labour or delivered within 24 hours. In induction group (B), induction was successful with single application of PGE2 in 41 (56.94\%) cases. The age groups were comparable in both the study groups. The mean gestational age was 38.9 completed weeks, which was same for both expectant and induction group. The study groups were comparable in terms of gravidity with p-value 0.278 .

\begin{tabular}{|c|c|c|c|c|}
\hline \multicolumn{2}{|c|}{ Labour Parameters } & \multicolumn{2}{|c|}{ Expectant Group (A) } & Induction Group (B) \\
\hline \multirow{2}{*}{ Bishop Score } & Unfavourable & \multicolumn{2}{|c|}{$30(41.67 \%)$} & $31(43.06 \%)$ \\
\hline & Favourable & \multicolumn{2}{|c|}{$42(58.33 \%)$} & $41(56.94 \%)$ \\
\hline \multicolumn{2}{|c|}{ Mean Bishop Score } & \multicolumn{2}{|c|}{$4.67 \pm 0.82$} & $4.61 \pm 0.81$ \\
\hline \multirow{2}{*}{\multicolumn{2}{|c|}{ Mean time to Active labour }} & $14.91 \pm 8$ & & $8.27 \pm 3.80$ \\
\hline & & \multicolumn{3}{|c|}{$\mathrm{p}$-value $<0.0001, \mathrm{HS}$} \\
\hline \multicolumn{2}{|c|}{ Mean duration of active labour } & $7.22 \pm 2.35$ & \multicolumn{2}{|r|}{$6.75 \pm 2.377$} \\
\hline \multirow{2}{*}{\multicolumn{2}{|c|}{ Mean PROM Delivery Interval }} & $22.36 \pm 7.04$ & & $15.5 \pm 7.03$ \\
\hline & & \multicolumn{3}{|c|}{$\mathrm{p}$-value $<0.0001, \mathrm{HS}$} \\
\hline \multirow{3}{*}{$\begin{array}{c}\text { Mode } \\
\text { of delivery }\end{array}$} & Vaginal & $57(79.19 \%)$ & $40(55.55 \%)$ & p-value $0.003, \mathrm{HS}$ \\
\hline & LSCS & $15(20.83 \%)$ & $31(43.06 \%)$ & p-value $0.004, \mathrm{HS}$ \\
\hline & Instrumental & 0 & $1(1.39 \%)$ & p-value $0.500, \mathrm{NS}$ \\
\hline
\end{tabular}

Table 2. Distribution of Study Subjects According to Labour Parameters

Bishop Score was comparable between both the groups $(p=0.1359)$. The mean time to active labour was $14.91 \pm 8.41$ hours for expectant group and 8.27 \pm 3.80 hours for induction group, and the difference was highly significant; as was the mean PROM to delivery interval, $22.36 \pm 7.04$ hours for expectant group and $15.5 \pm 7.03$ hours for induction group
$(\mathrm{P}=<0.0001, \mathrm{HS})$. There was a significantly higher rate of vaginal deliveries in expectant group and significantly higher rate of LSCS in induction group, with commonest indications for LSCS being foetal distress, failed induction and nonprogress of labour.

\begin{tabular}{|c|c|c|c|}
\hline Neonatal Outcome & Expectant Group (A) & Induction Group (B) & P - value \\
\hline Mean Apgar 1 min. \pm SD & $7.65 \pm 1.39$ & $7.69 \pm 1.14$ & $0.845, \mathrm{NS}$ \\
\hline Mean Apgar 5 min. \pm SD & $9.32 \pm 1.49$ & $9.44 \pm 1.14$ & $0.574, \mathrm{NS}$ \\
\hline Neonatal Morbidity & $23.61 \%$ & $18.06 \%$ & $0.412, \mathrm{NS}$ \\
\hline NICU Admission & $5.56 \%$ & $1.39 \%$ & $0.366, \mathrm{NS}$ \\
\hline Antibiotic Requirement & $47.22 \%$ & $23.61 \%$ & $0.002, \mathrm{HS}$ \\
\hline \multicolumn{2}{|r|}{} \\
\hline
\end{tabular}

There was no significant difference in the neonatal morbidity and NICU admissions between the two groups. APGAR score was also comparable between the two groups. However, antibiotic requirement was significantly higher in the expectant group.

\begin{tabular}{|c|c|c|c|c|}
\hline \multicolumn{2}{|c|}{ Maternal Morbidity } & Expectant Group (A) & Induction Group (B) & $P$ - value \\
\hline \multicolumn{2}{|c|}{ Signs of Chorioamnionitis } & $18 \%$ & $8.33 \%$ & $0.085, \mathrm{NS}$ \\
\hline \multicolumn{2}{|c|}{ Wound Complications } & $33.33 \%$ & $3.23 \%$ & $0.0045, \mathrm{HS}$ \\
\hline \multirow{2}{*}{$\begin{array}{l}\text { Mean Hospital Stay } \\
\text { (in days) }\end{array}$} & FTND & $1.84 \pm 1.22$ & $1.15 \pm 0.58$ & $0.0013, \mathrm{HS}$ \\
\hline & LSCS & $8.66 \pm 1.44$ & $8.12 \pm 0.50$ & $0.0683, \mathrm{NS}$ \\
\hline
\end{tabular}

Table 4. Distribution of Subjects According to Maternal Morbidity

There was a significantly higher rate of wound complications in the expectant group. Mean hospital stay was significantly longer in the expectant group in subjects with vaginal deliveries; however, the difference was not significant for women who underwent LSCS.

\section{DISCUSSION}

Premature Rupture of Membrane is a major obstetric problem. PROM occurs in approximately $5-10 \%$ of all pregnancies, of which approximately $80 \%$ occur at term (term PROM). ${ }^{2}$

PROM is not uncommon yet the management, even at term is controversial and there is no standard protocol for its management. The gestational age and the presence or absence of intra-amniotic infection (Chorioamnionitis) determine the initial management of the patient with PROM.

Active management in cases with PROM at term has been shown to reduce latency of labour following development of 
PROM. This is beneficial in terms of reduction of maternal and neonatal infection without much fear of increase in LSCS incidence due to labour induction. ${ }^{10,11,12}$

In a prospective study conducted by Chaudhari Snehamay et al,13 32.14\% (36/112) women went into spontaneous labour while under observation for 12-14 hours in expectant group. Ninety one percent of women required single application of PGE2 gel for labour induction in early induction group. Similar findings were observed by Yogesh Neena et al in their comparative study. ${ }^{14}$

Up to $40 \%$ of women with PROM at term have a cervix that is unfavourable for labour induction, i.e. a Bishop's score of less than 4.15 In the study conducted by Chaudhari Snehamay et al ${ }^{13} 36(32.43 \%)$ cases had favourable Bishop score in early induction group while 34 (30.35\%) cases had favourable Bishop score in expectant group whereas 76 $(67.56 \%)$ cases had unfavourable Bishop score in early induction group while $78(69.64 \%)$ cases had unfavourable Bishop score for expectant group; similar to our study.

Mary E. Hannath et $\mathrm{al}^{16}$ found that the mean time to active labour was 8.5 hours for induction with prostaglandin E2 gel while it was 16.0 hours for expectant group. They also found that the mean duration of active labour was 5.3 hours for induction with prostaglandin E2 gel group while it was 5.8 hours for expectant group. These findings were concordant with our study.

Shah Krupa \& Doshi Haresh ${ }^{17}$ found that the interval between the onset of PROM and delivery of the baby was 22 hours in the expectant group; whereas it was 13 hours in the early induction group. The difference was significant with a p-value of 0.001 . Early induction was useful to reduce maximum PROM-delivery interval from 42 to 27 hours. Kemal Gungorduk et al ${ }^{18}$ in their study of total 450 women, found that vaginal delivery within 24 hours of labour induction was significantly increased, with sustained release dinoprostone followed by oxytocin infusion $(78.5 \%$ vs. $63.3 \%$ ) versus oxytocin infusion only. Thus, in majority of studies investigators found significant reduction in PROM delivery interval in early induction group which is comparable to the findings of the present study.

Theoretically, immediate labour induction in women with an unfavourable cervix may reduce the incidence of maternal and neonatal infectious morbidity, yet raise the risk for operative vaginal or abdominal delivery. Alternatively, expectant management may be associated with a decreased incidence of caesarean delivery for failed induction, yet an increased incidence of maternal and neonatal infections.

In the study conducted by Shah Krupa \& Doshi Haresh,17 vaginal delivery and LSCS rate in induction group were quite comparable to that of expectant management group. However, in case of induction failure, percentage of LSCS increased up to $50 \%$. There was not much difference in incidences of caesarean delivery in expectant and immediate induction groups which were 22 and $24 \%$ respectively. This outcome was not in agreement with the findings in our study. Yogesh Neenaet al $^{19}$ In their comparative study also found comparable rates of LSCS between expectant and induction groups which were 24 and $25.33 \%$ respectively. Da krupa F et $\mathrm{al}^{20}$ were in agreement in their study in terms of higher incidence of cesarean delivery in induction group as compared to expectant group.
Mary E. Hannath et $\mathrm{al}^{16}$ et al observed no statistical difference in neonatal morbidity between induction group and expectant group. Shah Krupa \& Doshi Haresh ${ }^{17}$ observed similar rates of neonatal morbidity between induction group and expectant group. However, there was an increase in morbidity in subjects who required labour induction in 24 hours to $20 \%$ as compared to $2 \%$ in subjects who went into spontaneous labour in 24 hours. This finding was similar to the observations in the present study. In a study conducted by Dare MR et al, statistically significant higher rates of NICU admission and antibiotic requirment observed in expectant group than induction group. Fewer infants went to neonatal intensive care under planned management although no differences were seen in neonatal infection rates. ${ }^{3}$

Thus, increased rates of neonatal morbidity were observed with increase in duration of PROM delivery interval.

As the interval between membrane rupture and the onset of labour extends beyond 24 hours, the risk of maternal chorioamnionitis increases 5 -fold relative to women with a latency period of less than 24 hours. The risk of perinatal mortality increases with a latency period of more than 72 hours. ${ }^{9}$ Women who develop clinical chorioamnionitis have a $30 \%$ to $50 \%$ likelihood of requiring caesarean delivery due to dysfunctional labour, and approximately $10 \%$ of their neonates will have clinical signs of sepsis.4,21,22,23 Taking into consideration the data gathered, it seems like that the overall incidence of chorioamnionitis (clinical and other signs of chorioamnionitis) was higher in expectant group than induction group, although the difference was not statistically significant.

Shah Krupa \& Doshi Haresh ${ }^{17}$ observed $6 \%$ and $4 \%$ maternal morbidity rates in expectant and induction groups respectively. Mary E. Hannath et al 16 also observed higher incidence of maternal morbidity in the form of chorioamnionitis i.e. $1.7 \%$ in expectant group as compared to $0.7 \%$ in induction group. Significantly fewer women in the planned compared with expectant management groups had chorioamnionitis (RR, 0.74) or endometritis (RR, 0.30) according to Dare MR et al. ${ }^{3}$

\section{CONCLUSION}

60-70\% patients with term PROM go into spontaneous labour within 24 hours; and out of the remaining, labour will start within 72 hours in most. It is very important on the part of the obstetrician to effectively diagnose and manage this condition in order to avoid maternal and foetal complications, especially infection. It is advocated that labour should be induced early in such patients, as soon as the diagnosis of PROM is established. Mode of induction of labour is still a task. Prostaglandins are the most favoured drugs for the same. However, induction of labour does pose a risk of hyperstimulation and increased operative interference. Ultimately, it is the obstetrician's job to judiciously manage a patient with PROM for a favourable maternal and foetal outcome.

\section{REFERENCES}

[1] Larranaga-Azcarate C, Campo-Molina G, PerezRodrı'guez AF, et al. Dinoprostone vaginal slow release system compared to expectant management in the active treatment of premature rupture of the 
membranes at term: impact on maternal and fetal outcome. Acta obstetrica 2008;87(2):195-200.

[2] Duff P. Premature rupture of the membranes in term patients: induction of labor versus expectant management. Clin Obstet Gynecol 1998;41(4):883-91.

[3] Dare MR, Middleton P, Crowther CA, et al. Planned early birth versus expectant management (waiting) for prelabour rupture of membranes at term $(\geq 37$ weeks). Cochrane Database Syst Rev 2006;1:CD005302.

[4] Duff P, Huff RW, Gibbs RS. Management of premature rupture of membranes and unfavourable cervix in term pregnancy. Obstet Gynecol 1984;63(5):697-702.

[5] Conway DI, Prendiville WJ, Morris A, et al. Management of spontaneous rupture of the membranes in the absence of labor in primigravid women at term. Am J Obstet Gynecol 1984;150(8):947-51.

[6] Morales WJ, Lazar AJ. Expectant management of rupture of membranes at term. South Med J 1986;79(8):955-8.

[7] Cammu H, Verlaenen H, Perde MP. Premature rupture of membranes at term in nulliparous women: a hazard? Obstet Gynecol 1990;76(4):671-4.

[8] Hjertberg R, Hammarstrom M, Moberger B, et al: Premature rupture of the membranes (PROM) at term in nulliparous women with a ripe cervix. A randomized trial of 12 or 24 hours of expectant management. Acta Obstet Gynecol Scand 1996;75(1):48-53.

[9] Johnson JW, Daikoku NH, Niebyl JR, et al. Premature rupture of the membranes and prolonged latency. Obstet Gynecol 1981;57(7):547-56.

[10] Polzin WJ, Brady K. Mechanical factors in the etiology of premature rupture of the membranes. Clin Obstet Gynecol 1991;34(4):702-14.

[11] Bou-Resli MN, Al-Zaid NS, Ibrahim ME. Full-term and prematurely ruptured fetal membranes. An ultrastructural study. Cell Tissue Res 1981;220(2):263-78.

[12] Ozden S, Delikara MN, Avci A, et al. Intravaginal misoprostol vs expectant management in premature rupture of membranes with low bishop scores at term. Int J gynaecol obstet 2002;77(2):109-15.
[13] Chaudhuri S, Mitra NS, Pranab BK, et al. Premature rupture of membranes at term: immediate induction with PGE2 gel compared with delayed induction with oxytocin. J Obstet Gynecol India 2006;56(3):224-9.

[14] Lanier LR, Scarbrough RW, Fillingim DW, et al. Incidence of maternal and fetal complications associated with rupture of the membranes before the onset of labor. Am J Obstet Gynecol 1965;93:398-404.

[15] Yancey MK. Prelabor rupture of membranes at term: induce or wait? Medscape 1999;1(10). Available from: URL:htp//www.medscape.com.

[16] Hannah ME, Ohlsson A, Farine D, et al. Induction of labor compared with expectant management for prelabor rupture of the membranes at term. TERMPROM study group. The New England Journal of Medicine 1996;334(16):1005-10.

[17] Shah K, Doshi H. Premature rupture of membrane at term: early induction versus expectant management. The Journal of Obstetrics and Gynecology of India 2012;62(2):172-5.

[18] Güngördük K, Asicioglu O, Besimoglu B, et al. Labor induction in term premature rupture of membranes: comparison between oxytocin and dinoprostone followed 6 hours later by oxytocin. American Journal of Obstetrics \& Gynecology 2012;206(1):60-2.

[19] Neena Y, Agrawal Y, Kural MR. Foetal outcome in premature rupture of membrane at term: comparison of early induction versus expectant management in rural setup. International journal of medical and applied sciences 2013;2(4):119-23.

[20] da krupa GF, Cecatti JG, de Surita CFG, et al. Misoprostol versus expectant management in premature rupture of membranes at term. BJOG 2005;112(9):1284-90.

[21] Gunn GC, Mishell DR, Morton DG. Premature rupture of the fetal membranes: a review. Am J Obstet Gynecol 1970;106(3):469-83.

[22] Wagner MV, Chin VP, Peters CJ, et al. A comparison of early and delayed induction of labor with spontaneous rupture of membranes at term. Obstet Gynecol 1989;74(1):93-7.

[23] Gibbs RS, Duff P. Progress in pathogenesis and management of clinical intraamniotic infection. Am J Obstet Gynecol 1991;164(5 Pt 1):1317-26. 